\title{
Novel use of cryotherapy to control bleeding in advanced esophageal cancer
}

We report the first case of endoscopic cryotherapy to control bleeding in unresectable esophageal cancer. A 62-year-old Caucasian man with locally advanced esophageal adenocarcinoma was admitted with melena and symptomatic anemia. Medical history included chronic kidney disease, significant cerebrovascular disease, testicular cancer, and brain chordoma. Upper endoscopy revealed diffuse hemorrhage from the known infiltrative, circumferential mass extending $30-40 \mathrm{~cm}$ from the incisors ( Fig. 1). Hemostasis was attempted with both epinephrine injection and argon plasma coagulation but with limited success. The patient soon became dependent on transfusion; a total of 30 blood transfusions were required over a 2-week period.

Multiple noninvasive therapies had already been attempted for the cancer, including chemotherapy, external beam radiation therapy, brachytherapy, and photodynamic therapy, and no additional chemotherapy or radiation could be offered. Given the critical nature of the bleeding, a decision was made to attempt hemostasis using the CryoSpray Ablation System (CSA Medical ${ }^{\mathrm{TM}}$, Baltimore, Maryland, USA). A decompression tube was placed in the esophagus ( $\mathbf{F i g} \mathbf{2}$ ) over a Savary guide wire, and an open-tipped 7-Fr CryoSpray catheter was introduced through the biopsy channel of a standard endoscope. Low-pressure cryogen was delivered at $-196{ }^{\circ} \mathrm{C}$ via the catheter in pulses of 20 seconds to achieve three rapid freeze-thaw cycles ( Fig. 3). Immediate postprocedural hemostasis was achieved ( $\bullet$ Fig. 4). Over the next 2 weeks, the patient required only one blood transfusion, and this was temporally related to the incisional bleeding after central line placement. The patient expired 2 weeks later from multiorgan system failure after a prolonged course in the intensive care unit.

Endoscopic cryotherapy has been described previously to treat bleeding mucosal vascular lesions of the gastrointestinal tract [1-3]. The present case is the first published report of the use of cryoablation to achieve hemostasis in locally unresectable hemorrhagic esophageal cancer. Controlling bleeding in critically

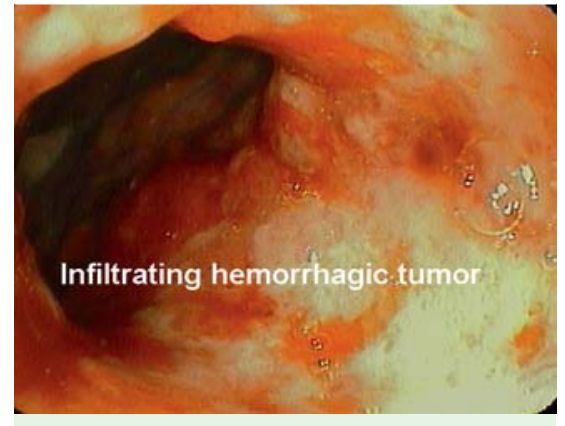

Fig. 1 Infiltrating, hemorrhagic esophageal adenocarcinoma extending $30-40 \mathrm{~cm}$ from the incisors.

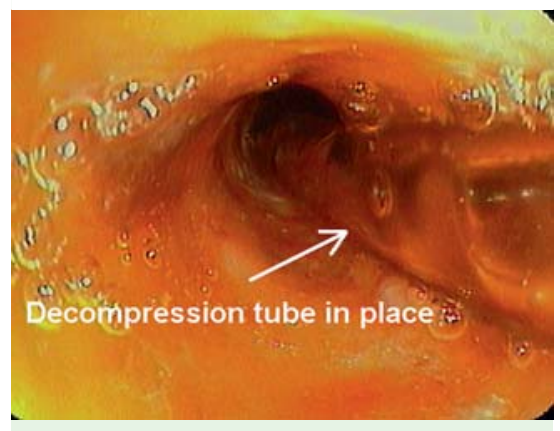

Fig. 2 Decompression tube (arrow) in the esophagus.

ill patients is often a difficult task, and cryotherapy offers an additional endoscopic modality to add to our armamentarium.

\section{Endoscopy_UCTN_Code_TTT_1AO_2AD}

\section{B. Shah, F. Schnoll-Sussman}

Department of Gastroenterology and Hepatology, New York Presbyterian Hospital - Weill Cornell Medical College, New York, USA

\section{References}

1 Pasricha PJ, Hill S, Wadwa KS et al. Endoscopic cryotherapy: experimental results and first clinical use. Gastrointest Endosc 1999; 49: 627-631

2 Kantsevoy SV, Cruz-Correa MR, Vaughn CA et al. Endoscopic cryotherapy for the treatment of bleeding mucosal vascular lesions of the GI tract: a pilot study. Gastrointest Endosc 2003; 57: $403-406$

3 Cho S, Zanati S, Yong E et al. Endoscopic cryotherapy for the management of gastric antral vascular ectasia. Gastrointest Endosc 2008; 68: 895-902

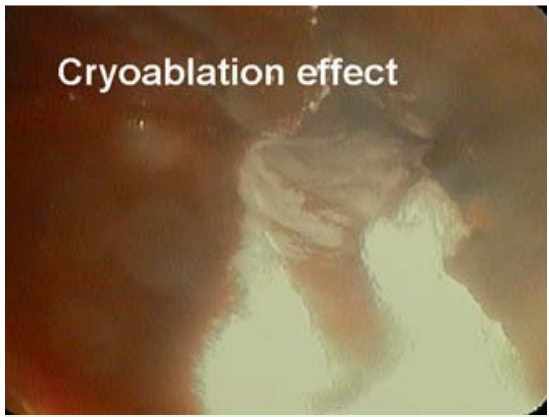

Fig. 3 Effect of cryoablation on the esophageal mucosa.

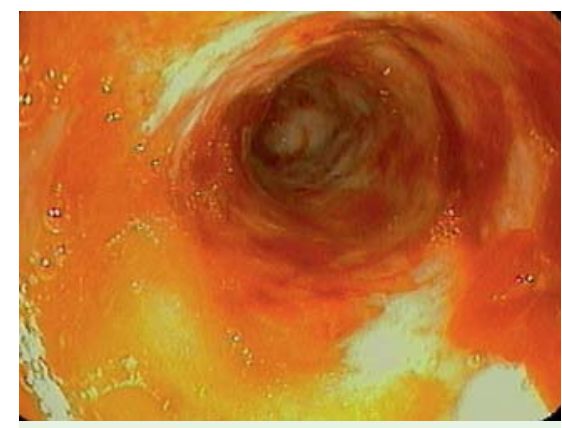

Fig. 4 Postprocedural hemostasis.

\section{Bibliography}

Dol $10.1055 / \mathrm{s}-0029-1215370$

Endoscopy 2010; 42 : E46

(c) Georg Thieme Verlag KG Stuttgart · New York . ISSN 0013-726X

\section{Corresponding author \\ M. B. Shah, MD}

Gastroenterology Fellow

Department of Gastroenterology and Hepatology New York Presbyterian Hospital - Weill Cornell Medical College

1305 York Avenue, 4th Floor

New York

NY 10021

USA

Fax: +646-962-0399

Mas9217@nyp.org 